\title{
Improved high-performance fully non-inductive discharge by optimizing the fast-ion confinement on EAST
}

EAST Team; Huang, J.; Qian, J.P.; Garofalo, A.M.; Gong, X.Z.; Wu, C.R.; Chang, J.F.; Zhang, J.; Du, H.F.; Wu, M.Q.

Total number of authors:

33

Published in:

Nuclear Fusion

Link to article, DOI:

10.1088/1741-4326/ab443a

Publication date:

2020

Document Version

Peer reviewed version

Link back to DTU Orbit

Citation (APA):

EAST Team, Huang, J., Qian, J. P., Garofalo, A. M., Gong, X. Z., Wu, C. R., Chang, J. F., Zhang, J., Du, H. F., Wu, M. Q., Hao, B. L., Yu, L. M., Zhang, X. M., Madsen, B., Salewski, M., Liang, L. Z., Li, J., Ding, S. Y., Zhong, G. Q., ... Wan, B. (2020). Improved high-performance fully non-inductive discharge by optimizing the fast-ion confinement on EAST. Nuclear Fusion, 60(1), [016002]. https://doi.org/10.1088/1741-4326/ab443a

\section{General rights}

Copyright and moral rights for the publications made accessible in the public portal are retained by the authors and/or other copyright owners and it is a condition of accessing publications that users recognise and abide by the legal requirements associated with these rights.

- Users may download and print one copy of any publication from the public portal for the purpose of private study or research.

- You may not further distribute the material or use it for any profit-making activity or commercial gain

- You may freely distribute the URL identifying the publication in the public portal 


\author{
IMPROVED HIGH PERFORMANCE FULLY \\ NON-INDUCTIVE DISCHARGE BY OPTIMIZING THE FAST-ION \\ CONFINEMENT ON EAST \\ J. HUANG ${ }^{1}$, J.P. QIAN ${ }^{1}$, A. M. GAROFALO ${ }^{2}$, X.Z. GONG ${ }^{1}$, C.R. WU ${ }^{1}$, J.F. CHANG ${ }^{1}$, J. ZHANG ${ }^{1}$, H.F. DU ${ }^{1}$,

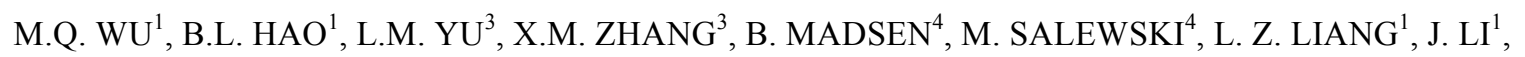 \\ S.Y. DING ${ }^{1}$, G.Q. ZHONG ${ }^{1}$, J.L. CHEN ${ }^{1}$, X. ZHU' ${ }^{1}$, L. ZENG ${ }^{1}$, E.Z. LI ${ }^{1}$, B. ZHANG ${ }^{1}$, Z. XU ${ }^{1}$, J.X. SU ${ }^{1}$, W.

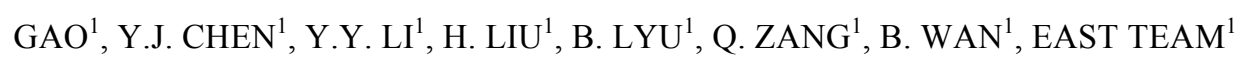 \\ ${ }^{1}$ Institute of Plasma Physics, Chinese Academy of Sciences, Hefei, Anhui, China \\ ${ }^{2}$ General Atomics, San Diego, California, USA \\ ${ }^{3}$ East China University of Science and Technology, Shanghai, China \\ ${ }^{4}$ Department of Physics, Technical University of Denmark, Kgs. Lyngby, Denmark
}

Corresponding author: juan.huang@ipp.ac.cn

\begin{abstract}
The long-pulse high-performance fully non-inductive plasma is one of the major scientific objectives on EAST using the ITER-like tungsten upper divertor. Understanding and optimizing the fast-ion behaviors is the critical issue to extend the performance on EAST. Recently, using both NBI (neutral beam injection) and RF (low hybrid, electron cyclotron and ion cyclotron) heating, fully non-inductive high- $\beta_{\mathrm{P}}$ scenarios with extension of fusion performance at high density and low rotation have been achieved with $\beta_{\mathrm{P}}$ up to $2.5, \beta_{\mathrm{N}}$ up to 2.0 and $\mathrm{H}_{98 \mathrm{y} 2}>1.1$, with the bootstrap current fraction $\left(\mathrm{f}_{\mathrm{BS}}\right)$ up to $50 \%$. For previous longpulse H-mode plasma at medium density, compared with RF-only discharges, when NBI is added into RF plasma $\beta_{\mathrm{p}}$ is increased from 1.2 to 2.0. In fact, $f_{\mathrm{BS}}$ for both discharges are nearly the same $\sim 22 \%$. The analysis shows that the increase in $\beta_{\mathrm{p}}$ is mostly due to fast ions which do not contribute significantly to the neoclassical bootstrap current. Thus, to obtain high performance plasmas with the improved bootstrap current fraction, key parameters (e.g. density, beam energy, etc.) are further optimized. Experimental results show that high density improves bootstrap fraction also by reducing fast-ion slowing down time and loss, as well as the lower beam energy mitigates fast-ion loss which is better for heating and CD performance. The extension of high performance fully non-inductive experiments on EAST at high density and zero/low NBI torque can offer unique contributions towards ITER and CFETR.
\end{abstract}




\section{INTRODUCTION}

For future fusion devices, e.g. ITER and CFETR, fast ions play a key role in the development of steady state operations, which can be sustained with the energy from fusion reactions and auxiliary heating (e.g. neutral beam injection (NBI), ion cyclotron resonant heating (ICRH)). Furthermore, fully non-inductive plasma current drive is also necessary to achieve and sustain steady state conditions. To minimize the power required for external non-inductive current drive relevant to high density fusion reactors, the intrinsic bootstrap current needs to be a significant portion of the total plasma current, which implies high poloidal-beta $\beta_{\mathrm{P}}$ plasmas $\left(\mathrm{f}_{\mathrm{BS}} \sim \varepsilon^{0.5} \mathrm{C}_{\mathrm{s}} \beta_{\mathrm{P}}\right)$ [1-4]. However, neoclassical bootstrap current will not be increased if high $\beta_{\mathrm{P}}$ is mostly achieved due to fast-ion contribution. Furthermore, high fast-ion $\beta$ can also drive Alfvén eigenmode (AE) instabilities, causing enhanced fast-ion transport beyond the classically expected level [5]. These modes can also redistribute fast-ion profile, reduce beam efficiency thus limiting the achievable $\beta_{\mathrm{N}}$, and/or enhance loss and damage the wall [6]. Manipulating fast-ion velocity space can control these instabilities and improve performance. During DIII-D steady-state scenario development, fast-ion transport was found to degrade confinement [7]. To minimize $\mathrm{AE}$ and fast-ion transport, the current profile and fast-ion pressure profile were optimized [8]. Experiments have also shown that changing the beam current and voltage can improve beam ion confinement by reducing fast-ion transport caused by AEs [9]. Recently, DIII-D/EAST joint high $\beta_{\mathrm{p}}$, low q95 experiments show that high density plasmas, with a Greenwald fraction up to $100 \%$, have reduced fast-ion slowing down time and correspondingly reduced AE activity [10].

The major goal of EAST is to demonstrate a long-pulse, high-performance, and fully noninductive regime to improve the scientific basis for ITER and CFETR. With the improvement of the auxiliary heating and current drive systems and the actively-cooled ITER-like monoblock tungsten divertor, a 100s steady-state H-mode $\left(\mathrm{H}_{98 \mathrm{y} 2} \sim 1.1\right)$ discharge has been achieved by radio frequency heating and current drive (RF-only: lower hybrid wave, electron cyclotron heating, ion cyclotron heating) $[11,12]$. Both co-I $\mathrm{I}_{\mathrm{P}}$ and counter-I $\mathrm{I}_{\mathrm{P}}$ neutral beam injectors are installed and essential to achieve advanced steady-state operation on EAST. Therefore, understanding fast-ion behaviour and related physical issues is a critical aspect to achieve the EAST scientific objectives. Accordingly, several complementary fast-ion measurements [13, 14] have been developed and validated on EAST, e.g. fast-ion D-alpha (FIDA), fast-ion loss 
detectors (FILDs), neutral particle analysers (NPA), neutron flux monitor and TOFED neutron spectrometers. With the enhanced heating and current drive systems, EAST has the capability to explore steady-state high-performance regimes in support of ITER and CFETR. Recently, the steady-state fully non-inductive high- $\beta$ regimes for higher bootstrap current fraction $\left(\mathrm{f}_{\mathrm{BS}} \sim 40-50 \%\right)$ were obtained at high density $\mathrm{f}_{\mathrm{GW}} \sim 0.6-0.8$ with $\mathrm{H}_{98}$, $\mathrm{y} 2>1.0$ [15]. Here we report an EAST discharge with high $\beta_{\mathrm{P}} \sim 2.5$ and $\beta_{\mathrm{N}} \sim 2.0$ using NBI which successfully demonstrated reduced fast-ion loss by increasing density to ne $4.7 \times 10^{19} \mathrm{~m}^{-3}$.

This paper is organized as follows. Section 2 describes characteristics of beam ions on EAST as well as the fast-ion loss as function of beam voltage and plasma density. Section 3 presents the comparison between RF-only and RF with NBI plasmas, along with TRANSP analysis that shows the relationship between higher $\beta_{\mathrm{P}}$ and the fast-ion contribution from NBI heating. Section 4 discusses the higher plasma density and lower beam voltage needed to reduce the fast-ion slowing down time and the orbit loss, and these effects on $\beta_{P}$ and $f_{B S}$. Finally, a brief summary is given in Section 5.

\section{BEAM ION CHARACTERISTICS ON EAST}

\subsection{Experimental method and analysis}

The neutral beam injection systems at EAST consist of both co- $\mathrm{I}_{\mathrm{P}}$ and counter- $\mathrm{I}_{\mathrm{P}}$ neutral beam injectors. Each beam injector consists of two ion sources. Each source can typically produce $2-4 \mathrm{MW}$ of beam power with an energy of $50-80 \mathrm{keV}$. As shown in Fig. 1(a), co-I $\mathrm{I}_{\mathrm{P}}$ sources located at the A-port are named as NBI1L, NBI1R, and counter-IP sources located at the F-port are named as NBI2L, NBI2R, with the dimensions of the NBI ports as $1358 \mathrm{~mm} \times 970 \mathrm{~mm}$. The power fractions of full, half and third energetic neutrals for NBI1L, NBI1R, NBI2L, NBI2R are 0.8:0.12:0.08, 0.83:0.1:0.07, 0.86:0.09:0.05 and 0.8:0.13:0.07, respectively, with injected ion source energy of $60 \mathrm{keV}$. The tangential radii of the co- $\mathrm{I}_{\mathrm{P}}$ and counter- $\mathrm{I}_{\mathrm{P}}$ sources are $1.26 \mathrm{~m}, 0.73 \mathrm{~m}, 0.61 \mathrm{~m}$, and $1.14 \mathrm{~m}$, respectively. The geometry of the beam in NUBEAM is set as: the ion source's dimension with a height $\times$ width of $48 \mathrm{~m} \times 12 \mathrm{~cm}$; the vertical focal length at $7.2 \mathrm{~m}$ and infinite horizontal focal length; and vertical /horizontal divergence of $1.2^{\circ} / 0.6^{\circ}$.

To address high $\beta_{\mathrm{p}}$ regimes with fully non-inductive current drive, experiments were designed to study the fast-ion characteristics of each beam line on EAST. Fig. 1(b) shows an 
H-mode discharge, 81450, with four beam sources fired sequentially throughout the discharge as NBI1L, NBI1R, NBI2L and NBI2R. The other plasma parameters were as follows: plasma current $\mathrm{Ip}=0.4 \mathrm{MA}$ in a counter-clockwise direction, toroidal magnetic field of $2.5 \mathrm{~T}$ also in the counter-clockwise direction, and an electron density of $4.5 \times 10^{19} \mathrm{~m}^{-3}$. Each beam was injected with beam energy around of $60 \mathrm{keV}$ for roughly $1.1 \mathrm{~s}$, which is significantly longer than a slowing down time $(\sim 100 \mathrm{~ms})$. The neutron rate (Fig. 1(b)) measured by a neutron flux monitor diagnostic (235U FC) shows a large reduction $(\sim 50-60 \%)$ during ctr- $\mathrm{I}_{\mathrm{P}}$ beam injection, relative to co-Ip injection, indicating that the number of confined fast-ions is substantially decreased. Therefore, to evaluate fast-ion loss, TRANSP/NUBEAM was applied [16]. The calculated neutron rates labelled as magenta dots are also shown in Fig. 1(b) compared with the measured neutron rates, assuming that the fast-ion transport is completely classical. The overestimates between the calculated and measured neutron rates are $4.5 \%$, $7.6 \%, 7.3 \%, 3.2 \%$, corresponding to NBI1L, NBI1R, NBI2L, NBI2R, respectively. It was found that the fast-ion loss was dominated by two factors: the orbit loss, and the shinethrough loss. The orbit loss fraction for each beam (NBI1L, NBI1R, NBI2L, NBI2R) was evaluated at $7.7 \%, 13.5 \%, 51.3 \%, 48.5 \%$, demonstrating that significant orbit loss arises from counter-I $\mathrm{I}_{\mathrm{P}}$ beam injection. In Fig. 2, described in constants-of-motion space while marking topological boundaries between the different types of orbits [17], the numerical code ORBIT, was then used to compare the lost fast-ion numbers from the co- $\mathrm{I}_{\mathrm{P}}$ beam (NBI1L) and ctr- $\mathrm{I}_{\mathrm{P}}$ beam (NBI2R) sources. Here, the numbers of Monte Carlo markers were set as $2 \times 10^{5}$ particles for both sources with equal weight. The results of this analysis also show the larger orbit loss from the counter-I $I_{P}$ beam. Specifically, using the TRANSP/NUBEAM birth profiles, various trajectories of energetic particle calculated by ORBIT show that the dominant loss orbits are trapped lost orbits and co-passing lost orbits. Here, the TRANSP/NUBEAM distribution functions for the different beam lines will be further studied in the future together with measurements of fast-ion velocity-space via FIDA tomography on EAST [18]. The shine-through loss fraction for each beam (NBI1L, NBI1R, NBI2L, NBI2R) was calculated at $5.0 \%, 10.1 \%, 10.5 \%, 5.7 \%$, demonstrating that the more tangential beamlines have lower shine-through loss compared with the more vertical beamlines.

\subsection{Beam ion loss characteristics}

A previous study showed that beam ion prompt loss and ripple loss is dramatically reduced with increased plasma current [19]. Other key parameters (e.g. density, beam voltage) were 
investigated in an attempt to reduce the fast-ion slowing down time and loss for each beam line. Fig. 3 shows the shine-through loss versus beam voltage and electron density for the beamlines. The result shows that the more tangential beamlines (NBI1L, NBI2R) have lower shine-through loss than less tangential beams (NBI1R, NBI2L). This shine-through loss can also be decreased by reducing beam voltage and increasing electron density. When the beam voltage is decreased from $60 \mathrm{kV}$ to $50 \mathrm{kV}$, the shine-through loss is reduced by up to $\sim 35 \%$. Furthermore, when the electron density is increased from $4.4 \times 10^{19} \mathrm{~m}^{-3}$ to $5 \times 10^{19} \mathrm{~m}^{-3}$, the shine-through loss is decreased by $\sim 28 \%$ from $3.9 \%$ to $2.8 \%$ for NBI1L.

Fig. 4 shows the orbit loss against beam voltage and electron density for all beam lines, with the ctr- $\mathrm{I}_{\mathrm{P}}$ beam showing much larger loss as expected. With reduced beam voltage, the orbit loss tends to decrease weakly on all beamlines except NBI2R, where no clear trend is observed at all. Lower beam voltage can lead to smaller fast-ion orbits with less orbit loss, but also can lead to more fast-ion deposition in the plasma edge with more orbit loss. These counteracting effects might explain the weak trend of the orbit loss against the beam voltage. Similarly, there is no clear trend in the orbit loss versus the electron density in the density range $\left(4.4 \times 10^{19} \mathrm{~m}^{-3}\right.$ to $\left.5 \times 10^{19} \mathrm{~m}^{-3}\right)$. Here, increasing the electron density will result in shorter fast-ion slowing down time (evaluated at $36 \mathrm{~ms}, 33 \mathrm{~ms}, 31 \mathrm{~ms}$ at rho 0 for the NBI1L beam line corresponding to density with $4.4 \times 10^{19} \mathrm{~m}^{-3}, 4.7 \times 10^{19} \mathrm{~m}^{-3}, 5 \times 10^{19} \mathrm{~m}^{-3}$, respectively), which decreases orbit losses. Contrarily, higher density may also lead to more deposition in the plasma edge with more orbit loss. These counteracting effects might also explain the weak trend of the orbit loss against the electron density. The experimental investigation of the fastion loss measured by FILDs and fast-ion distribution from velocity-space tomography [2022] from FIDA measurements with the different beam settings and plasma parameters will be described in future work, and will aid the understanding of energetic particle physics both in long pulse H-mode plasmas on EAST, and in the future for ITER and CFETR.

\section{EFFECT OF FAST-ION IN FULLY NON-INDUCTIVE DISCHARGES ON EAST}

A $100 \mathrm{sec}$ long-pulse, fully non-inductive H-mode plasma with good energy confinement $\left(\mathrm{H}_{98(\mathrm{y}, 2)} \sim 1.1\right)$ has been successfully achieved on EAST using RF heating and current drive. This milestone was achieved through integrated control of the wall conditioning and recycling, plasma configuration, divertor heat flux, particle and impurity control, and the effective coupling of multiple RF heating and current drive (H\&CD) sources [1]. However, the normalized plasma pressure in these discharges was still too low with respect to ITER and 
CFETR requirements. To explore high fusion performance in the fully non-inductive regime, balanced neutral beam injection was implemented and was essential to achieve advanced steady-state operation on EAST. Fig. 5 shows time traces of two fully non-inductive discharges: the RF-only shot 66740 is similar to a typical $100 \mathrm{sec}$ long-pulse discharge $\left(\mathrm{n}_{\mathrm{e}} \sim 3.5 \times 10^{19} \mathrm{~m}^{-3}, \mathrm{q}_{95} \sim 6.3, \beta_{\mathrm{p}} \sim 1.2, \mathrm{H}_{98, \mathrm{y} 2} \sim 1.1, \mathrm{P}_{\mathrm{RF}} \sim 4.0 \mathrm{MW}\right.$ with $\left.\mathrm{P}_{\mathrm{ICRF}} \sim 0.6 \mathrm{MW}\right)$, and shot 70187 with both NBI and RF $\left(\mathrm{n}_{\mathrm{e}} \sim 3.3 \times 10^{19} \mathrm{~m}^{-3}, \mathrm{q}_{95} \sim 6.7, \beta_{\mathrm{p}} \sim 2.0, \mathrm{H}_{98, \mathrm{y} 2} \sim 1.25, \mathrm{P}_{\mathrm{RF}} \sim 4.0 \mathrm{MW}\right.$ with $\left.\mathrm{P}_{\mathrm{ICRF}} \sim 0.6 \mathrm{MW}, \mathrm{P}_{\mathrm{NBI}} \sim 2.8 \mathrm{MW}\right)$. In Table 1, TRANSP analysis shows that, while $\beta_{\mathrm{p}}$ and $\mathrm{H}_{98, \mathrm{y} 2}$ are higher in the discharge with both NBI and RF, the bootstrap current fraction for both shots is nearly identical at $\sim 22 \%$ as shown in the bottom row of Fig. 5(a). The calculated total plasma energy for shot 70187 and shot 66740 is $\sim 149 \mathrm{~kJ}$ and $\sim 118 \mathrm{~kJ}$, respectively. The fastion energy is around $55 \mathrm{~kJ}$ for shot 70187 , which contributes $\sim 37 \%$ to the total plasma energy. For the RF-only shot 66740 , the fast-ion energy from ICRF minority heating is $8 \mathrm{~kJ}$, roughly $7 \%$ of the total plasma energy. Therefore, the higher $\beta_{p}$ for shot 70187 is primarily due to fast-ions from NBI, which do not contribute significantly to the neoclassical bootstrap current. Thus, to obtain high performance plasmas with improved confinement and reduced fast-ion contribution to the total plasma pressure, while simultaneously increased the bootstrap current, key parameters (e.g. density, plasma current, beam energy, etc.) were further optimized as described in the next section to reduce the fast-ion slowing down time and orbit loss, when NBI-heating is applied.

\section{EXTENSION OF HIGH PERFORMANCE FULLY NON-INDUCTIVE DISCHARGES WITH REDUCED FAST-ION LOSS}

In recent experiments, steady-state fully non-inductive scenarios in NBI-heated plasmas with improved fusion performance have been demonstrated on EAST with a bootstrap current fraction up to $\sim 50 \%$ and improved confinement $\mathrm{H}_{98, \mathrm{y}_{2}}>1.2$ at high density $\mathrm{f}_{\mathrm{GW}} \sim 0.6-0.8$. For shot 80339, shown in Fig.6, a fully non-inductive discharge $\left(\mathrm{V}_{\text {loop }} \sim 0\right)$ with plasma current $\mathrm{I}_{\mathrm{P}} \sim 0.4 \mathrm{MA}$ and toroidal field $\mathrm{B}_{\mathrm{T}} \sim 2.5 \mathrm{~T}$, improvement plasma confinement $\left(\mathrm{H}_{98, \mathrm{y} 2} \sim 1.25\right)$ was

achieved with $\beta_{\mathrm{p}} \sim 2.5$ and $\beta_{\mathrm{N}} \sim 2.0$ at an increased electron density of $\mathrm{n}_{\mathrm{e}} \sim 4.7 \times 10^{19} \mathrm{~m}^{-3}$ $\left(\mathrm{f}_{\mathrm{GW}} \sim 0.75\right)$. In this discharge, the total $\mathrm{RF}$ power was $\sim 3.7 \mathrm{MW}\left(\mathrm{P}_{\mathrm{LHW}} \sim 2.7 \mathrm{MW}\right.$ and $\mathrm{P}_{\mathrm{ECH}} \sim 1.0 \mathrm{MW}$ ), and the total NBI power was $2.4 \mathrm{MW}$ with co- $\mathrm{I}_{\mathrm{P}}$ and counter- $\mathrm{I}_{\mathrm{P}}$ neutral beam injections ( $\left.\mathrm{P}_{\mathrm{NBI} 1 \mathrm{R}} \sim 0.9 \mathrm{MW} @ 60 \mathrm{kV}, \mathrm{P}_{\mathrm{NBI} 1 \mathrm{~L}} \sim 0.9 \mathrm{MW} @ 60 \mathrm{kV}, \mathrm{P}_{\mathrm{NBI} 2 \mathrm{~L}} \sim 0.6 \mathrm{MW} @ 50 \mathrm{kV}\right)$. 
The LH current drive efficiency is lower in shot 80339 with higher density of $\mathrm{n}_{\mathrm{e}} \sim 4.7 \times 10^{19} \mathrm{~m}^{-3}$ compared to the lower density of $\mathrm{n}_{\mathrm{e}} \sim 3.3 \times 10^{19} \mathrm{~m}^{-3}$ in shot 70187 , with $\mathrm{f}_{\mathrm{LHCD}}$ reduced from $\sim 70 \%$ to $\sim 36 \%$, shown in Table 2 also with each current component fraction for both shots. Preliminary ONETWO analysis shows that the bootstrap current fraction is increased up to $47 \%$ for higher density shot 80339 (two times higher compared to shot 70187), which can be understood based on two factors: density gradients are more efficient in driving bootstrap current [23], and the reduced fast-ion slowing down time at higher density increases the thermal (bootstrap generating) contribution to the total plasma pressure. The profile of fastion pressure is shown in Fig. 7, a comparison of this shot with the previous lower density discharge 70187. The analysis has evaluated the fast-ion contribution to total plasma energy and the effects on confinement and transport in this high- $\beta$ fully non-inductive plasma, and predicts a significantly decreased fast-ion pressure vs total pressure. Alignment of bootstrap current and total current is shown in Fig. 8 , where the ECH current driven fraction is $\sim 4 \%$ and NBI current drive fraction is $\sim 13 \%$. Therefore the increase in bootstrap current with higher density nearly compensates the drop in LHCD efficiency, maintaining fully noninductive CD performance with help of slightly increased NBCD in this shot. Operation at higher density and higher $\beta_{\mathrm{P}}$ increased $\mathrm{f}_{\mathrm{bs}}$ and self-consistently broadened the current density profile, leading to a slightly reverse shear profile (Fig.8), which further contributes to the increase in energy confinement.

\section{SUMMARY}

The main goal for EAST is to investigate an approach to high performance, fully noninductive, long-pulse H-mode operation under fusion relevant conditions. A high bootstrap current fraction plasma regime is desirable for steady-state tokamak operation because it reduces the demands on external non-inductive current drive. To improve confinement and increase the bootstrap current with NBI heating on EAST, the plasma density and the beam energy have been simultaneously varied in experiments and simulations with a focus on fastion loss. Experimental results show that significant orbit loss occurs primarily from counter$I_{P}$ beams, compared with co- $I_{P}$ beams. The shine-through loss can be reduced by lower beam voltage and higher density. Recently, fully non-inductive high- $\beta$ scenarios with NBI have been demonstrated at high density $\mathrm{f}_{\mathrm{GW}} \sim 0.6-0.8$, in which $\mathrm{f}_{\mathrm{BS}}$ is up to $40-50 \%$ with $\mathrm{H}_{98 \mathrm{y} 2}>1.1$. An example high performance discharge with $\beta_{\mathrm{P}}$ up to 2.5 and $\beta_{\mathrm{N}}$ up to 2.0 was successfully demonstrated with zero loop voltage at $\mathrm{n}_{\mathrm{e}} \sim 4.7 \times 10^{19} \mathrm{~m}^{-3}$. Although lower LH current driven 
efficiency has been observed at high density, the analysis shows that the bootstrap current fraction is increased by roughly a factor 2 due to 1 ) the decreased fast-ion slowing down time and consequently the reduced fast-ion contribution to total plasma pressure at high density, and 2) the increased contribution of the density gradient to the bs current. Therefore the increase in BS current with higher density nearly compensates the drop in LHCD efficiency, maintaining fully noninductive CD performance.

Increasing plasma current is another straightforward way to reduce orbit loss, which will be explored for a range of plasma discharges in the future. To address high performance steady state operation on EAST, as well as future fusion reactor scenarios, further experiments will focus on Alfvén eigenmode (AE) instabilities and their effects on fast-ion transport and distribution, which can limit the achievable high performance (e.g. $\beta_{\mathrm{N}}$ ) in fully non-inductive long pulse $\mathrm{H}$-mode operation.

\section{ACKNOWLEDGEMENTS}

This work is supported by National Natural Science Foundation of China under Grant No. 11575249, National Magnetic Confinement Fusion Science Program of China under Grant Nos. 2015GB110005, 2014GB109004, 2015GB102000.

\section{REFERENCES}

[1] X. Gong, et al., "Development of fully non-inductive scenario at high bootstrap current fraction for steady state tokamak operation on EAST and DIII-D”, $25^{\text {th }}$ IAEA Int. Conf. on Fusion Energy, St Petersburg, Russia (2014).

[2] A.M. Garofalo, et al., "Compatibility of internal transport barrier with steady-state operation in the high bootstrap fraction regime on DIII-D”, Nucl. Fusion 55 (2015) 123025 (11pp).

[3] J.P. Qian, et al., "Advances in the high bootstrap fraction regime on DIII-D towards the $\mathrm{Q}=5$ mission of ITER steady state", Nucl. Fusion 57 (2017) 056008 (7pp).

[4] A.M. Garofalo, et al., "Joint DIII-D/EAST research on the development of a high poloidal beta scenario for the steady state missions of ITER and CFETR", Plasma Phys. Control. Fusion 60 (2018) 0140343 (13pp).

[5] W.W. Heidbrink, "Basic physics of Alfvén instabilities driven by energetic particles in toroidally confined plasmas", Phys. Plasmas 15 (2008) 055501. 
[6] M. Ishikawa, et al., "Observation of confinement degradation of energetic ions due to Alfvén eigenmodes in JT-60U weak shear plasmas”, Nucl. Fusion 46 (2006) S898-S903.

[7] W.W. Heidbrink, et al., "Confinement degradation by Alfvén-eigenmode induced fast-ion transport in steady-state scenario discharges”, Plasma Phys. Control. Fusion 56 (2014) 095030 (14pp).

[8] C.T. Holcomb, et al., "Fast-ion transport in qmin $>2$, high- $\beta$ steady-state scenarios on DIII-D”, Phys. Plasmas 22 (2015) 055904.

[9] D.C. Pace, et al., "Manipulating energetic ion velocity space to control instabilities and improve tokamak performance", $59^{\text {th }}$ annual meeting of the American physical society division of plasma physics, Milwaukee (2017).

[10] J. Huang, et al., "Manipulating energetic ion velocity space to control instabilities and improve tokamak performance", $60^{\text {th }}$ Annual meeting of the American physical society division of plasma physics, Portland (2018).

[11] B.N. Wan et al., "Recent advances in EAST physics experiments in support of steadystate operation for ITER and CFETR”, Nucl. Fusion (2019) https://doi.org/10.1088/1741$\underline{4326 / \mathrm{ab0396}}$

[12] X. Gong et al., "Integrated operation of steady-state long pulse H-mode in EAST", Nucl. Fusion 59 (2019) 086030.

[13] J. Huang et al., "Energetic particle research on EAST", $3^{\text {rd }}$ EAST/DIII-D joint planning workshop, Beijing (2017).

[14] J. Zhang, J. Huang, et al., "Fast-ion D-alpha measurements using a bandpass-filtered system on EAST', Rev. Sci. Instrum. 89 (2018) 10D121.

[15] J. Huang, et al., "Internal transport barrier dynamics at high poloidal beta on DIII-D and extensions towards high confinement scenarios for a fusion reactor", 60th APS-DPP, Oral Talk, 5-9 Nov 2018, Portland, Oregon.

[16] B. Geiger, et al. "Fast-ion transport in low density L-mode plasmas at TCV using FIDA spectroscopy and the TRANSP code", Plasma Phys. Control. Fusion 59 (2017) 115002.

[17] R.B. White, “The Theory of Toroidally Confined Plasmas”, Imperial College, London (2001).

[18] B. Madsen, et al., "Velocity-space tomography from synthetic FIDA measurements at EAST”, $45^{\text {th }}$ EPS on Plasma Physics, 2-6 July 2018, Prague.

[19] B. Wu et al., "Calculation of prompt loss and toroidal field ripple loss under neutral beam injection on EAST”, Plasma Phys. Control. Fusion 59 (2017) 025004. 
[20] M. Salewski et al., "High-definition velocity-space tomography of fast- ion dynamics", Nucl. Fusion 56 (2016) 106024.

[21] M. Weiland et al., "Enhancement of the FIDA diagnostic at ASDEX Upgrade for velocity space tomography” Plasma Phys. Control. Fusion 58 (2016) 025012.

[22] B. Madsen et al., "Velocity-space tomography using prior information at MAST", Rev. Sci. Instrum. 89 (2018) 10D125.

[23] O. Sauter et al., "Neoclassical conductivity and bootstrap current formulas for general axisymmetric equilibria and arbitrary collisionality regime", Phys. Plasmas 22 (2015) 055904.

\section{List of Captions}

Figure 1. (a) Top view on EAST tokamak with four beam lines installed in A-port and F-port, named as NBIIL, NBIIR, NBI2L, NBI2R. (b) Beam-ion characteristic study with a sequential beam line injection throughout the H-mode discharge 81450 with beam voltage $60 \mathrm{kV}$, plasma current 0.4MA with various calculated (as magenta dots) and measured neutron yields for each beam.

Figure 2. Classification of different orbit types [17] of beam ions with $E_{0} \sim 45 \mathrm{keV}$ on EAST for (a) co-I $I_{P}$ tangential beam NBIIL, and (b) ctr-I $I_{P}$ tangential beam NBI2R with magnetic moment $\mu$ normalized by $E / B_{0}$ against canonical angular momentum $P_{\zeta}$ normalized by the poloidal flux at the wall $\Psi_{w}$. Here, the particle energy is $E$, and the magnetic field at the magnetic axis is $B_{0}$.

Figure 3. The shine-through loss versus (a) beam voltage, and (b) electron density for the 4 beamlines (NBIIL, NBIIR, NBI2L, NBI2R).

Figure 4. The prompt loss versus (a) beam voltage, and (b) electron density for the 4 beamlines (NBIIL, NBIIR, NBI2L, NBI2R).

Figure 5 (a). Comparison of two fully non-inductive discharges: shot 70187 with NBI and $R F$; shot 66740 with RF-only; (b) profiles of total and thermal pressure@9.0s (shot 66740) and@5.1s (shot 70187), labelled by vertical dash line in Fig 5(a).

Figure 6. Time traces for high performance, fully non-inductive discharge 80339 with high $f_{B S}$ at high density: normalized poloidal beta, normalized beta, loop voltage, $H$-factor, Greenwald density fraction, NBI power, LHW power and ECRH power. 
Figure 7. Decreased fast-ion pressure at high-density /low beam energy in shot 80339, comparing with the previous lower density discharge 70187.

Figure 8. Alignment of bootstrap current, drive current, ohmic current and total current components vs current profile from ONETWO/TRANSP in high $\beta_{P}$ fully non-inductive discharge80339@5.1s labeled byvertical dash line in Figure 6.

TABLE 1. TRANSP/NUBEAM analysis for shot 70187 with NBI and RF; shot 66740 with RF-only.

\begin{tabular}{ccc}
\hline Parameter & $66740 @ 9 \mathrm{~s}$ & $70187 @ 5.1 \mathrm{~s}$ \\
\hline Total stored energy & $118 \mathrm{~kJ}$ & $149 \mathrm{~kJ}$ \\
Fast-ion energy & $8 \mathrm{~kJ}$ & $55 \mathrm{~kJ}$ \\
$\beta_{\mathrm{p}}$ & 1.13 & 1.95 \\
$\beta_{\mathrm{p}_{\_} \text {fast-ion }}$ & 0.137 & 1.4 \\
$\beta_{\mathrm{p}_{-} \text {beam-ion }}$ & 0 & 1.14 \\
$\mathrm{f}_{\mathrm{BS}}$ & $21 \%$ & $22 \%$
\end{tabular}

TABLE 2. Current Components in both of shots \#70187 and \#80339

\begin{tabular}{ccc}
\hline & $70187 @ 5.1 \mathrm{~s}$ & $80339 @ 5.1 \mathrm{~s}$ \\
\hline Electron Density $\left(\mathrm{ne} / \mathrm{n}_{\mathrm{G}}\right)$ & 0.55 & 0.75 \\
Poloidal Beta $\left(\beta_{\mathrm{p}}\right)$ & 1.95 & 2.5 \\
Bootstrap Current & $22 \%$ & $47 \%$ \\
LH Current Drive & $70 \%$ & $36 \%$ \\
NB Current Drive & $7 \%$ & $13 \%$ \\
EC Current Drive & $1 \%$ & $4 \%$ \\
\hline
\end{tabular}


Fig 1(a)

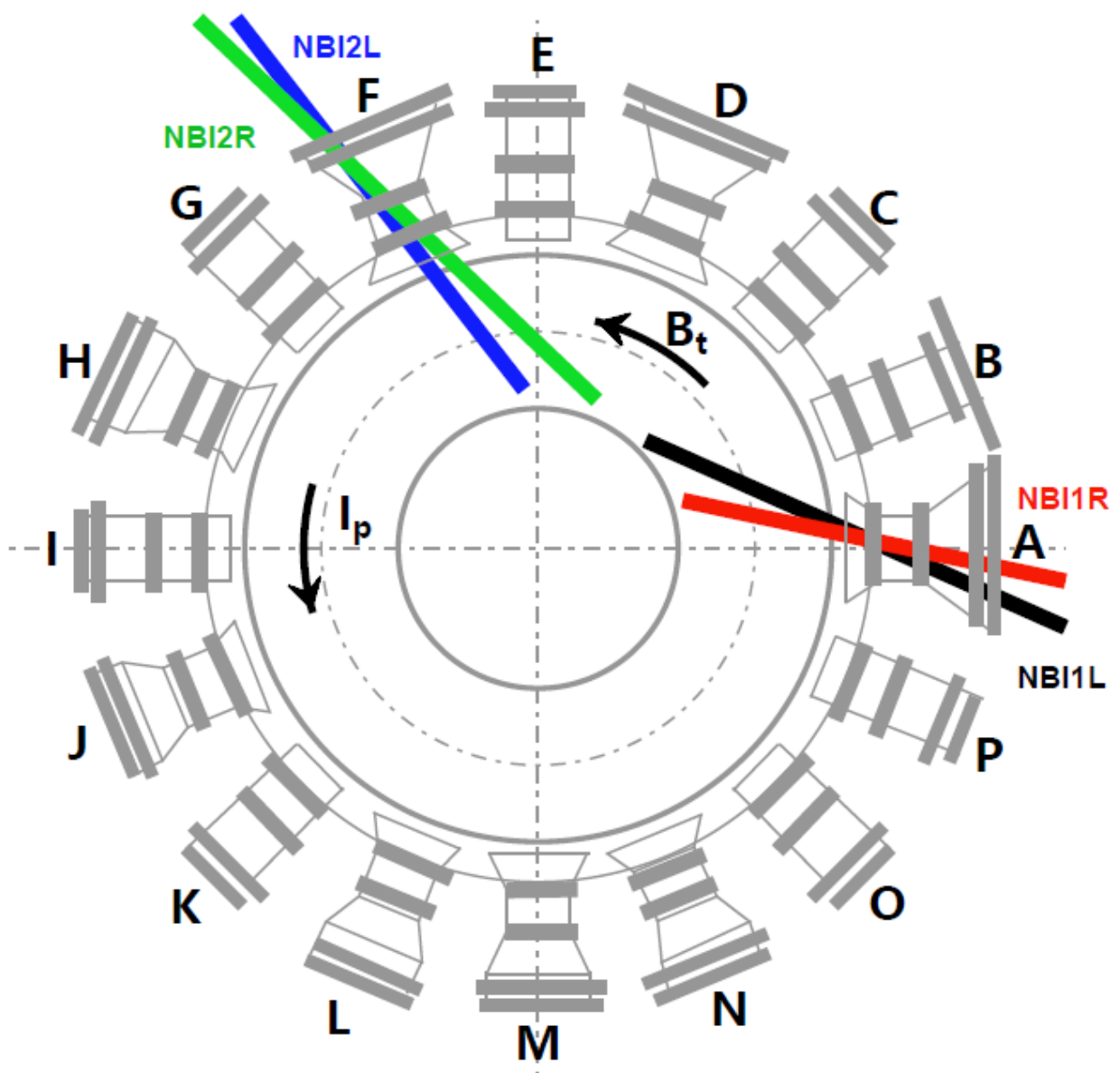


Fig 1(b)
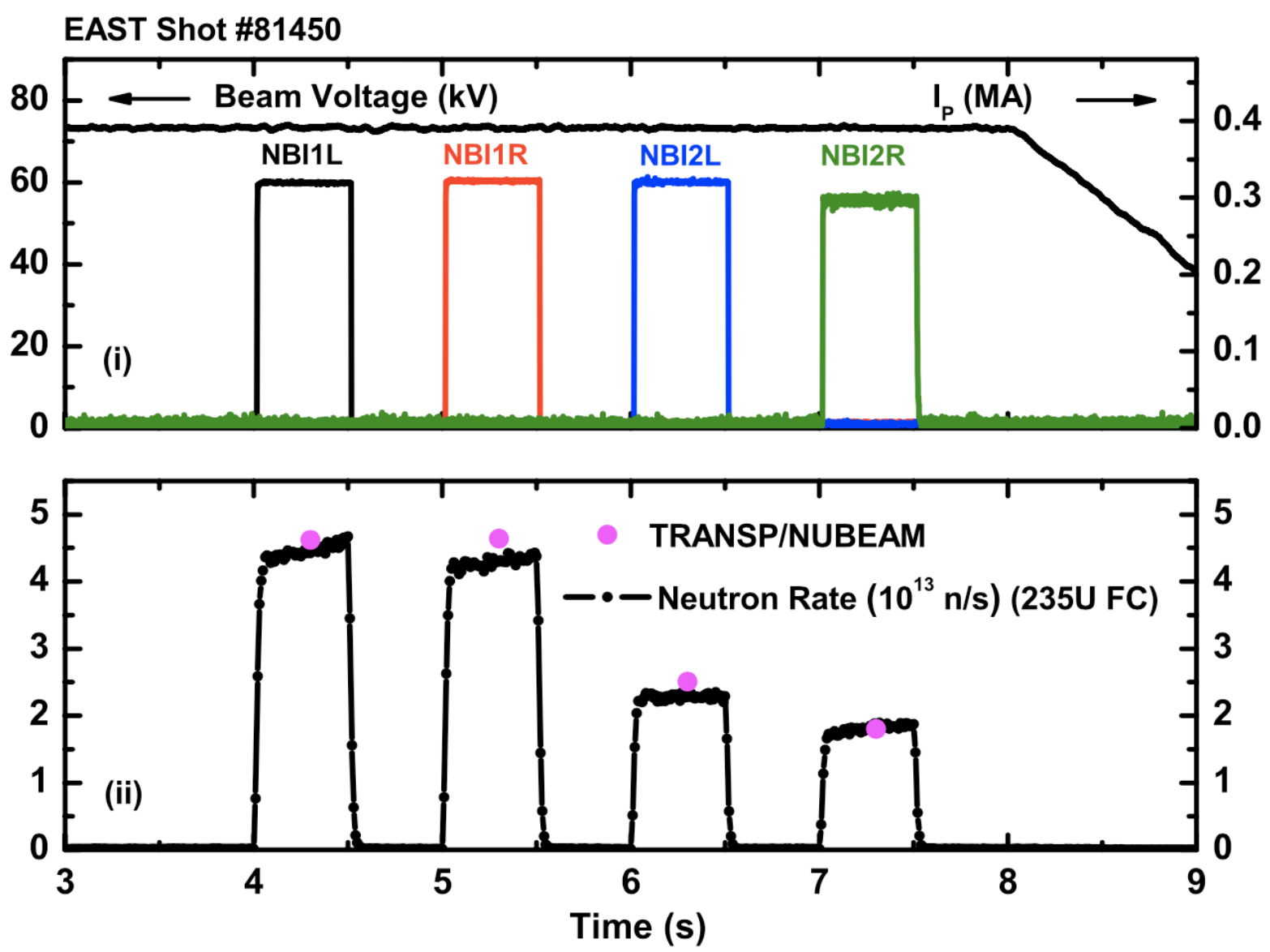
Fig 2
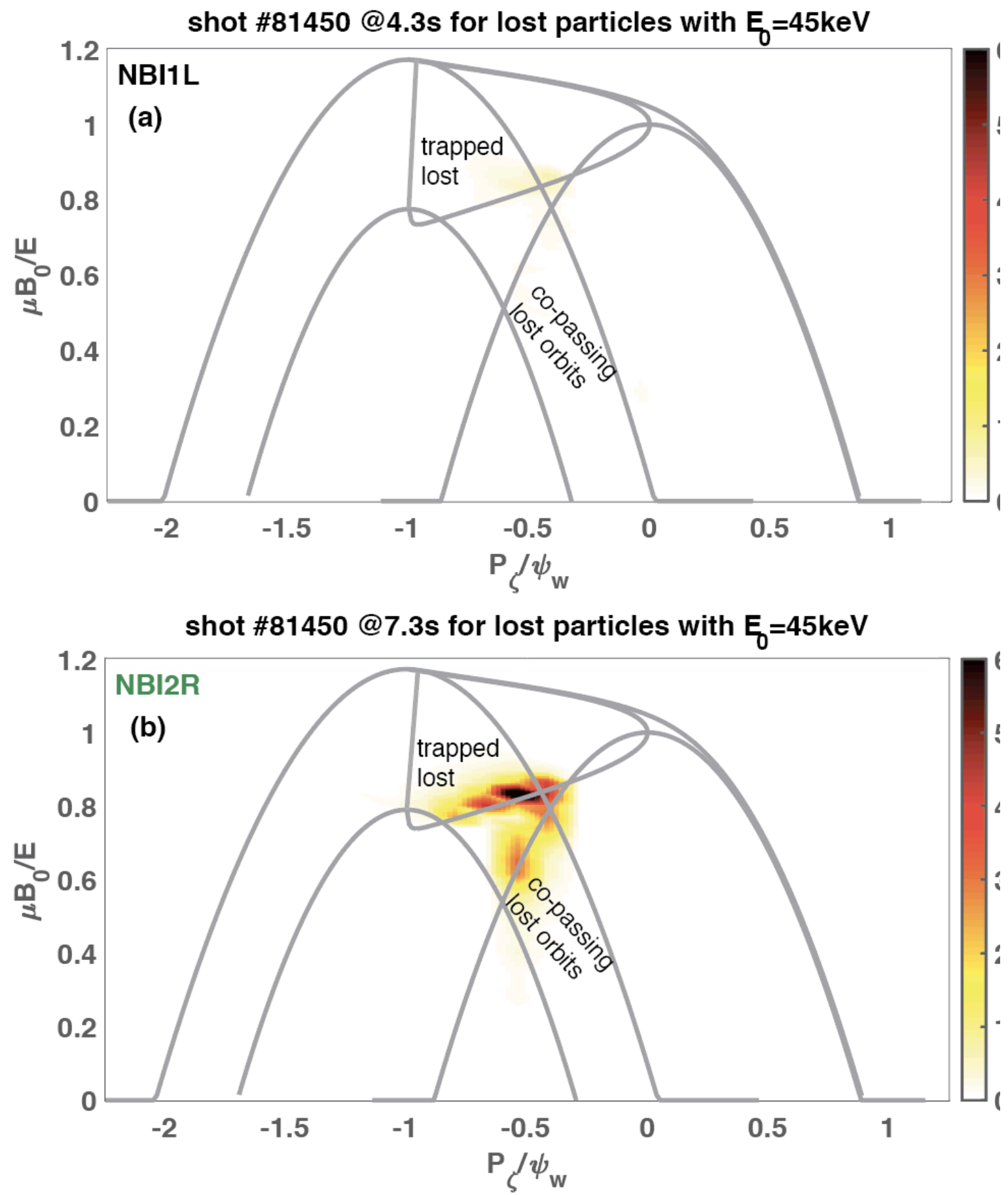
Fig 3(a)

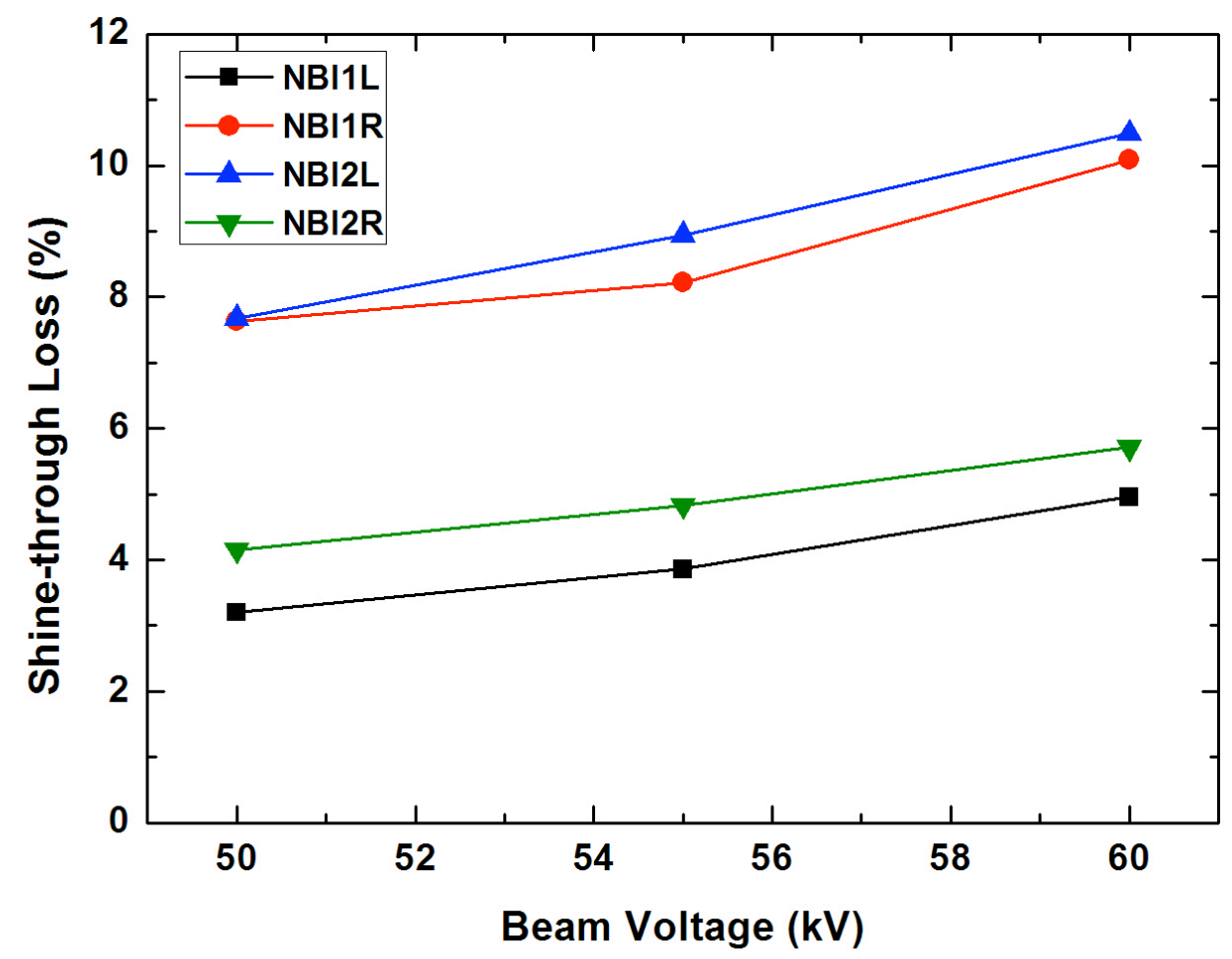

Fig 3(b)

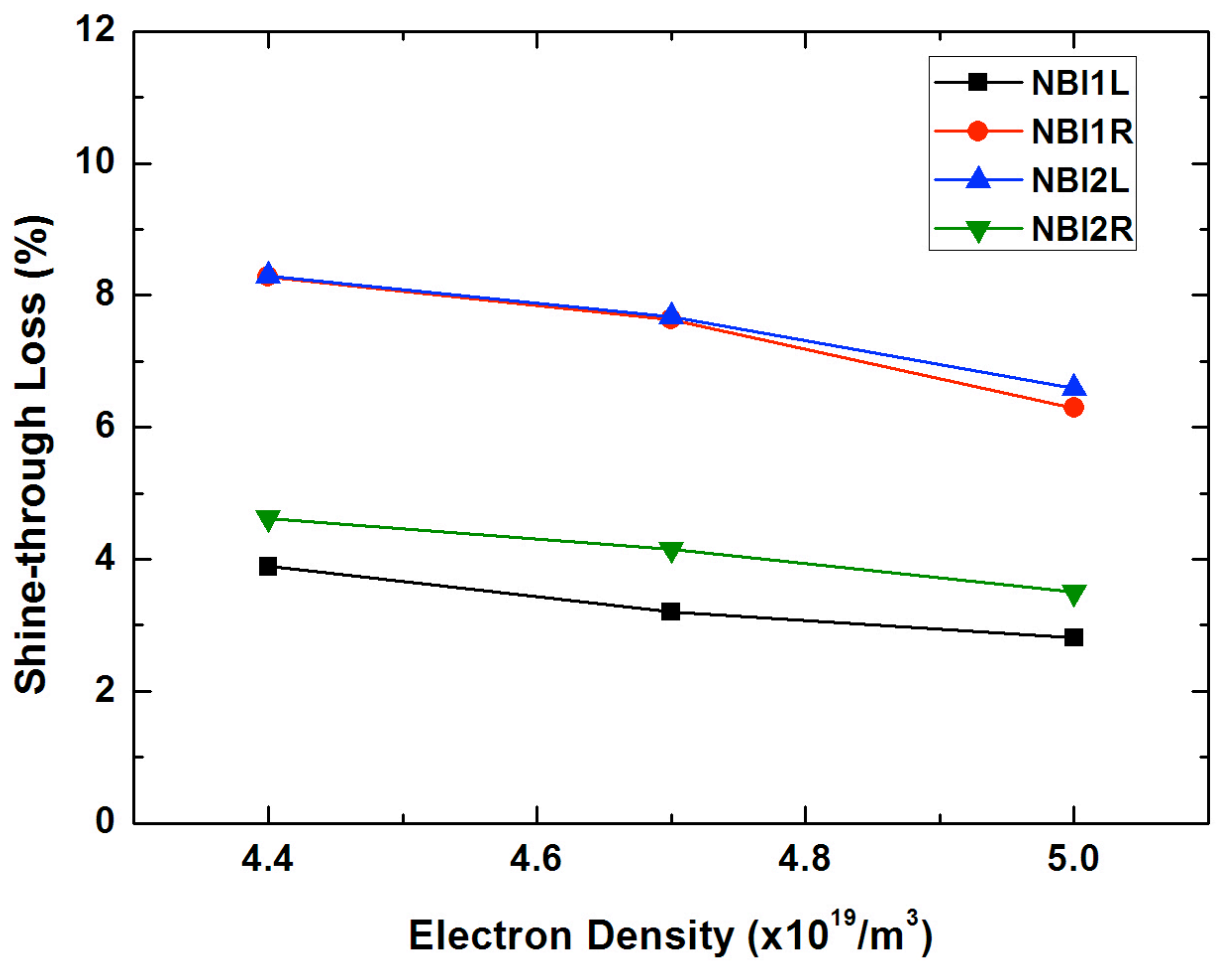


Fig 4(a)

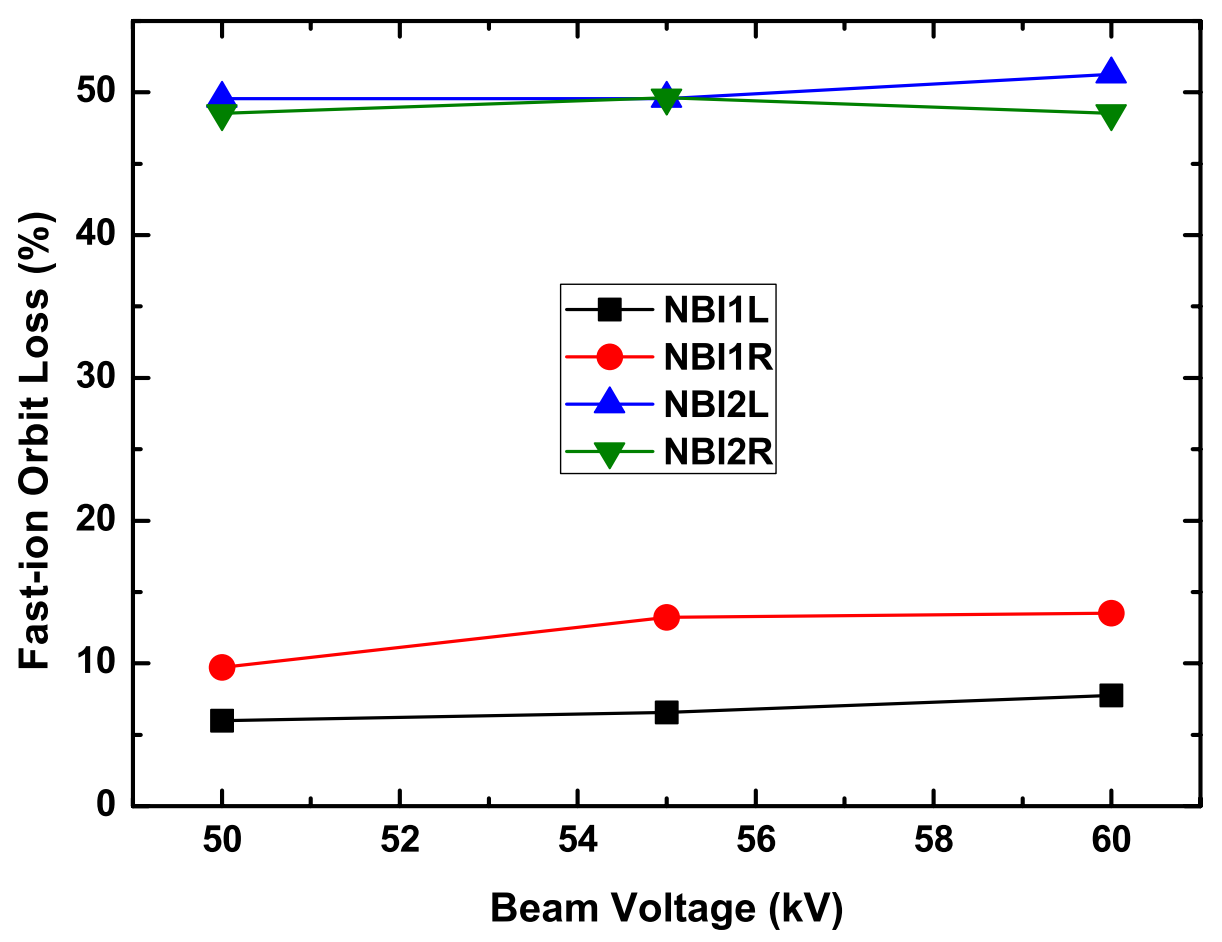

Fig 4(b)

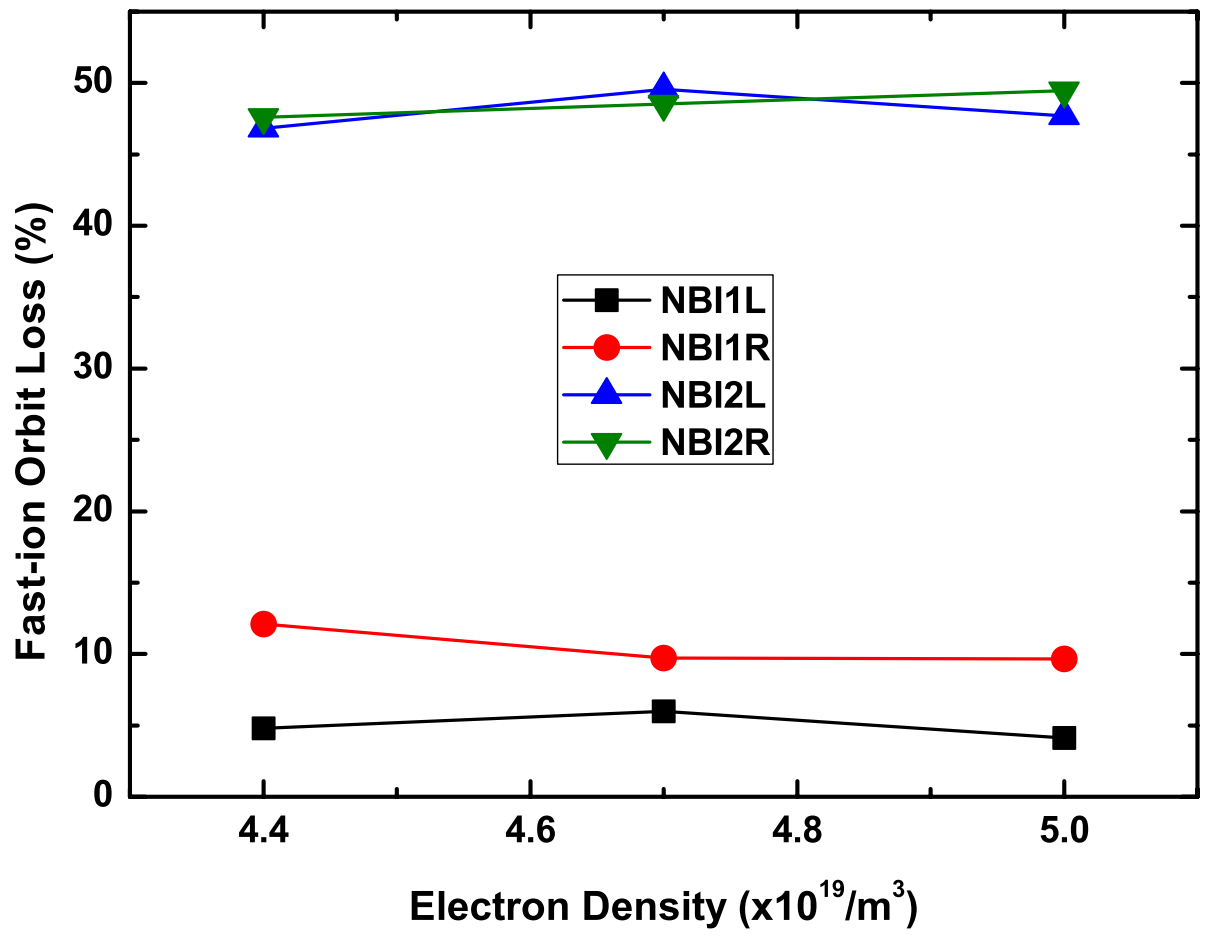

Fig 5(a) 


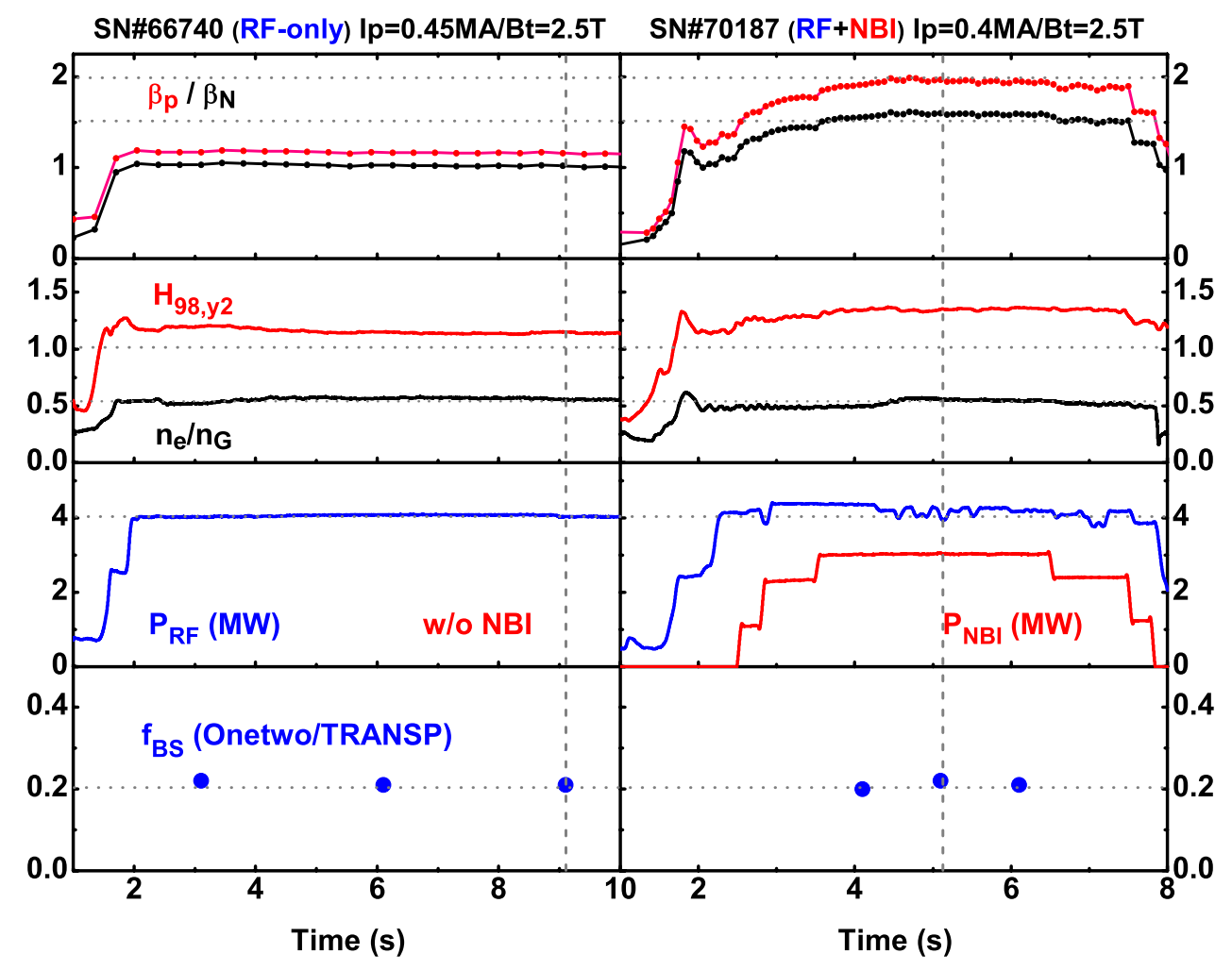

Fig 5(b)

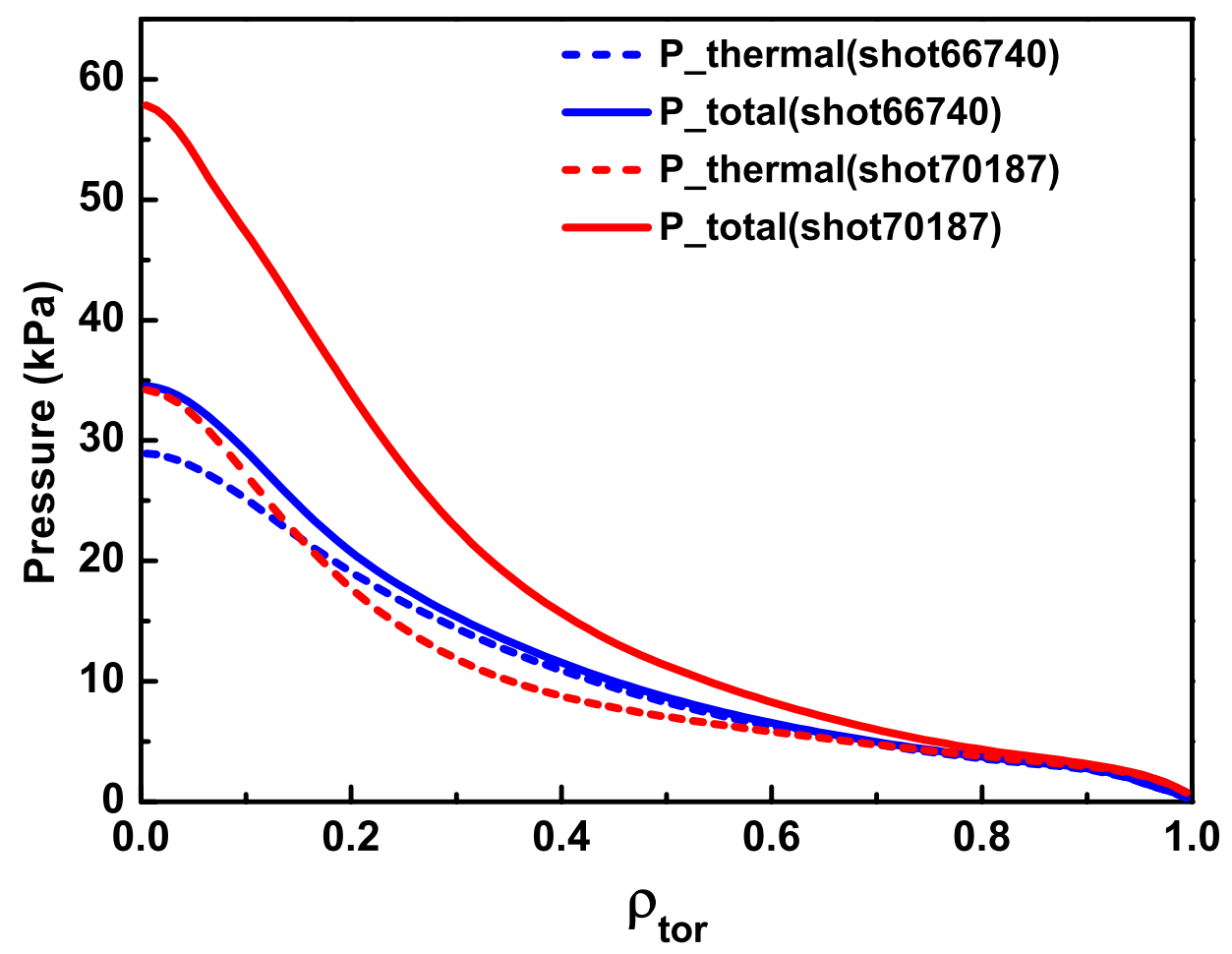


Fig 6

EAST Shot\#80339 Ip=0.4MA/B $t=2.5 T / U S N$

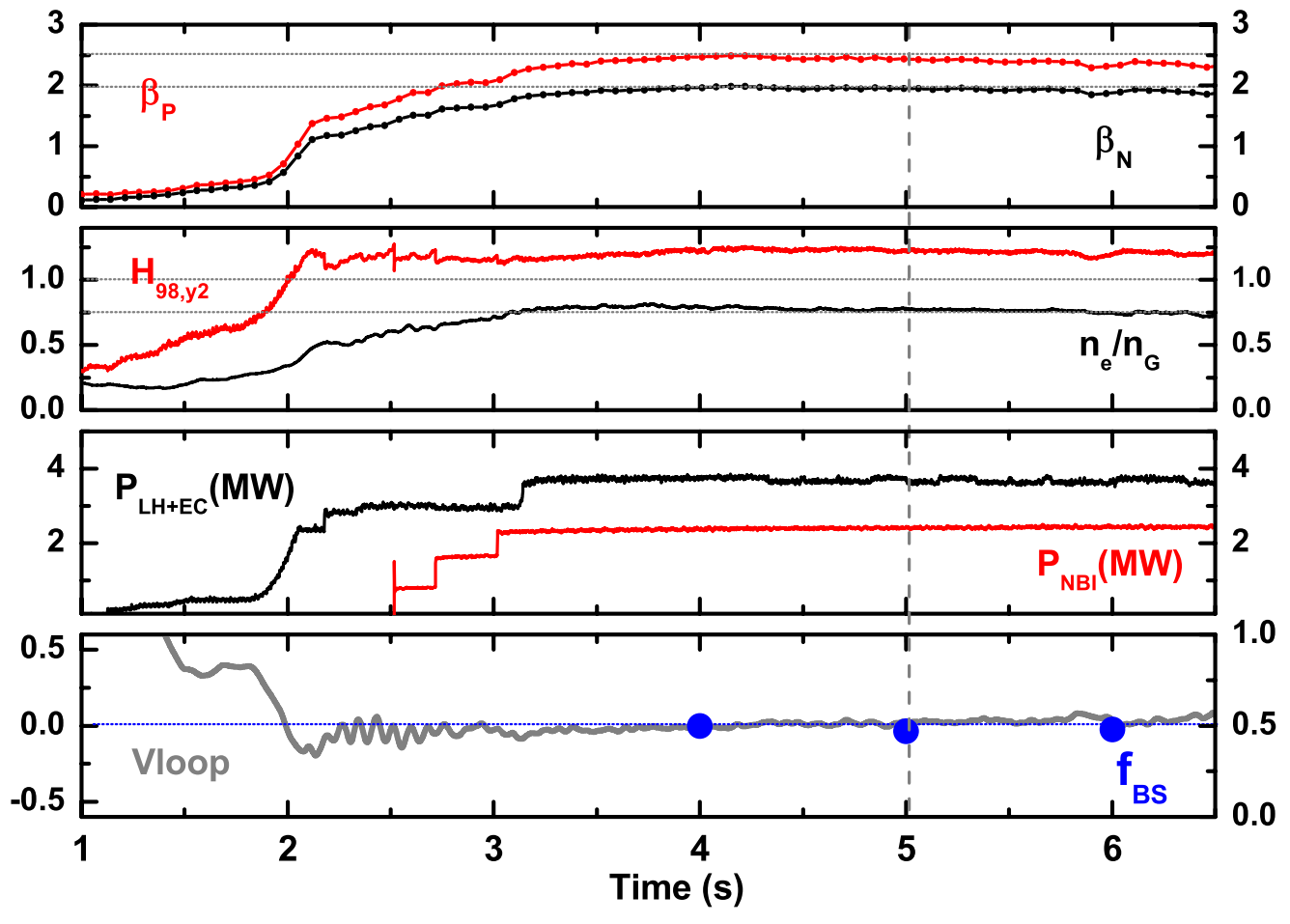

Fig 7

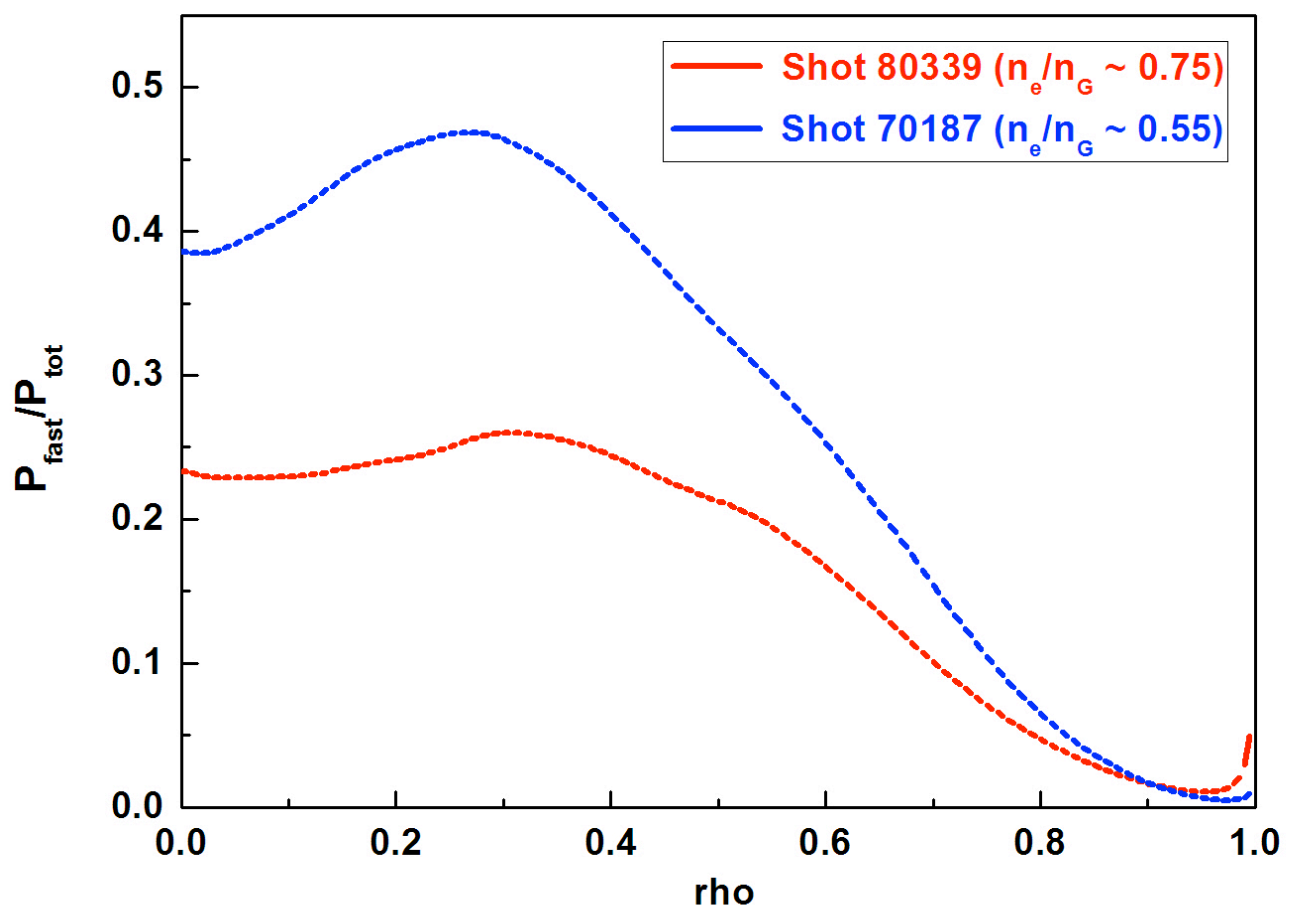


Fig 8

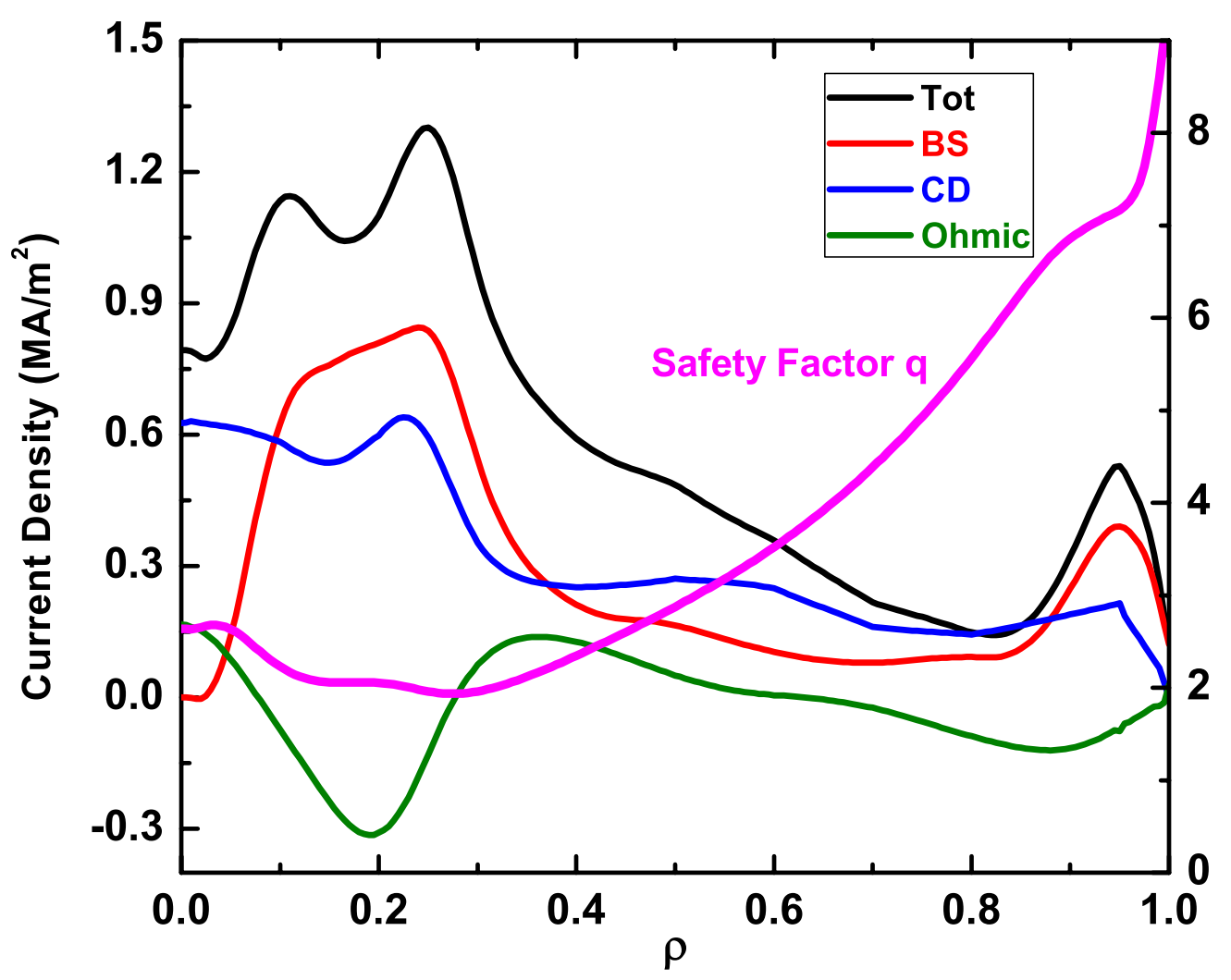

